\title{
QUE CIDADÃO DEVEMOS FORMAR? OS DESAFIOS DO ENSINO DE HISTÓRIA NA EDUCAÇÃO BÁSICA
}

\author{
WHAT KIND OF CITIZEN SHOULD WE EDUCATE? TEACHING HISTORY \\ CHALLENGES IN BASIC EDUCATION
}

\author{
Cléia Maria Alves ${ }^{1}$, Anna Rafaella de Paiva Dantas², Francisco das Chagas Silva \\ Souza ${ }^{3}$
}

${ }^{1}$ Instituto Federal de Educação, Ciência e Tecnologia do Rio Grande do Norte. Programa de PósGraduação em Educação Profissional e Tecnológica, Brasil, cleiamary2009@hotmail.com

2Instituto Federal de Educação, Ciência e Tecnologia do Rio Grande do Norte. Programa de PósGraduação em Educação Profissional e Tecnológica, Brasil, anarpaiva1@hotmail.com

${ }^{3}$ Instituto Federal de Educação, Ciência e Tecnologia do Rio Grande do Norte. Programa de PósGraduação em Educação Profissional e Tecnológica, Brasil, chagas.souza@ifrn.edu.br

AR T I CLE IN F O

Article history:

Received 2018-09-05

Accepted 2019-02-01

Available online 2019-02-07
Palavras-chave: Ensino de história. Sociedade capitalista. Juventude. Mundo do trabalho. Cidadão emancipado.

Keywords: History teaching. Capitalist society. Youth. World of work. Emancipated citizen.

RESUMO. O artigo analisa e discute os desafios e possibilidades do ensino de História na Educação Básica, para a formação do jovem cidadão para mundo do trabalho, frente às mudanças sócio-políticas e econômicas controladas pelos princípios do neoliberalismo. Buscamos discutir e evidenciar as consequências do modelo educacional destinado aos jovens das classes populares, que sinalizam para uma formação unilateral e excludente, que atende somente aos anseios e necessidades do capital. Assim, analisamos como o ensino de História pode contribuir para a construção de uma cidadania que contemple a formação humana integral e emancipatória de forma que o jovem seja capaz de compreender e transformar a realidade em que está inserido, contribuindo para uma sociedade mais justa e igualitária. Como metodologia, utilizamos a pesquisa bibliográfica a partir de pesquisadores do ensino de História, a exemplo de Bittencourt (2013), Fonseca (1993), Silva (2012), entre outros autores que discutem também a abordagem das temáticas que envolvem Trabalho, Educação e Sociedade.

ABSTRACT. This study aims to analyze and discuss the challenges and possibilities of History teaching in basic education, as well as the education of young citizens to the world of work, in the face of the sociopolitical and economic changes that permeate society controlled by the principles of neoliberalism. We aim to discuss and highlight the consequences of the educational model that is designed to educate young people from the low-income classes, that indicate a unilateral, exclusionary education that only meets the yearnings and needs of the capital. Thus, we analyzed how the teaching of History can contribute to the development of a citizenship that considers the emancipatory and integral human formation in such a way that the young people are able to understand and change the reality in which they are inserted, cooperating to the development of a just and egalitarian society. A methodology, we used bibliographical research from researchers of History teaching, such as Bittencourt (2013), Fonseca (1993), Silva (2012), among other authors who also discuss the approach to the themes involving Work, Education and Society. 


\section{Introdução}

Na sociedade capitalista, a categoria trabalho assume uma dimensão mercadológica, pautada no ensino de caráter instrumental, reforçando a dualidade estrutural na educação em detrimento de uma formação humana integral, omnilateral ou politécnica, dirigida para o exercício da cidadania e articulada à emancipação humana.

As propostas curriculares atuais, pautadas no ideário neoliberal, estão preocupadas em identificar e preparar os jovens para os ditames do sistema capitalista, cada vez mais globalizado, projetando um modelo de "cidadania" articulado aos seus interesses, conferindo aos jovens apenas o papel de trabalhador, produtor e consumidor. Assim, são muitos os desafios que os jovens das classes populares enfrentam diante de um modelo educacional segregacionista, excludente, que visa somente preparar para as atividades periféricas do mundo do trabalho.

Diante desse cenário, neste artigo, objetivamos refletir acerca do ensino de História na Educação Básica e o seu papel formativo de um cidadão crítico e politizado que irá se inserir no mundo do trabalho não apenas como um desenvolvedor de tarefas mecânicas. Nosso foco é discutir como o ensino de História pode contribuir para a formação de jovens cidadãos críticos, emancipados, reflexivos e que assumem o compromisso de construir uma sociedade mais justa e igualitária.

Dividimos o artigo em dois momentos. No primeiro, discutimos a relação entre o trabalho e a educação a partir da retórica capitalista neoliberal e as consequências para a classe trabalhadora. No segundo, analisamos os desafios e as possibilidades para o ensino de História, no que diz respeito ao seu papel formativo do jovem cidadão, para que este possa atuar de maneira autônoma e crítica diante das mudanças sócio-políticas no mundo do trabalho.

\section{Educação e mercado de Trabalho}

O conceito de cidadania, por ser historicamente construído, vem sendo bastante discutido e disseminado nos discursos acadêmicos e políticos, como também nas questões educacionais. No ensino de História, esse termo tem sido utilizado desde a existência da disciplina como obrigatória nos currículos brasileiros, sobretudo no seu papel formador de identidades nacionais. Entretanto, sobre o conceito de cidadania, nas propostas curriculares para o ensino de História, Bittencourt (2013, p. 22), afirma que: 
A ideia de cidadania social que abarca os conceitos de igualdades, de justiça, de diferenças, de lutas e de conquistas, de compromissos e de rupturas tem sido apenas esboçada em poucas propostas. E mais ainda, existe uma dificuldade em explicitar a relação entre a cidadania social e a política, e entre a cidadania e trabalho.

Dessa forma, é necessário enfatizar o conceito de cidadania explicitando a relação entre o papel do indivíduo e o da coletividade, bem como a formação política dos alunos, implicando para uma revisão aprofundada desse conceito a partir do modelo capitalista vigente.

O ensino de História na contemporaneidade é permeado por desafios no que diz respeito à formação de cidadãos críticos, emancipados e agentes de transformação da realidade, que possam inserir-se no mundo do trabalho. Os modelos educacionais estão sempre ligados às funções políticas e econômicas relacionados às ideologias dominantes, ancorados em um projeto societário hegemônico, com centralidade e fortalecimento na dimensão econômica (MOURA, 2013).

Nessa perspectiva, a educação destinada ao jovem tem sido unidimensional, voltada para a formação de competências destinadas à inserção destes no mercado do trabalho, em detrimento de uma formação humana, que integra os conhecimentos em sua totalidade tendo em vista uma concepção emancipatória.

O modelo de educação com centralidade na economia, reforça a dualidade estrutural na Educação Básica brasileira, com ênfase no Ensino Médio. Conforme Moura (2013), isso ocorre de maneira que, enquanto os filhos da elite recebem uma formação de caráter propedêutico, aos filhos das classes populares é destinada uma formação de caráter instrumental.

No contexto econômico neoliberal, as políticas educacionais destinadas aos jovens, filhos das classes trabalhadoras, constituem-se na oferta de programas e projetos de alívio à pobreza, constituídas de formações aligeiradas, profissionalizantes e de caráter assistencialista.

Diante disso, o Estado, ao invés de implementar e consolidar políticas que promovam a equidade educacional para inserção dos jovens no mundo do trabalho, implementa "[...] programas e projetos que resultam em medidas compensatórias contribuindo para construção de uma cidadania aviltada, precarizada, mitigada. Enfim, da formação de meios ou de quase cidadãos, uma inclusão excludente". (MOURA, 2013, p.129)

Nessa perspectiva, Moura (2013) acrescenta que essa dicotomia educacional constitui-se em um "apartheid que é coerente com a sociedade neoliberal, pois afinal, ela se 
nutre da desigualdade ao mesmo tempo em que se a alimenta, já que é essa a substância vital da competitividade". (MOURA, 2013, p.112).

Não é de hoje que o modo de produção capitalista exige cada vez mais que os jovens adquiram a empregabilidade e qualificação profissional numa determinada área do conhecimento para atender às demandas do mercado. Entretanto, na atualidade, o neoliberalismo tem aumentado essas exigências como pressuposto para a inserção no mercado, como afirma Moura (2013, p. 110):

[...] O modo de produção capitalista vem se tornando hegemônico nos últimos séculos em escala global e, atualmente, em sua fase neoliberal, patrocina a exacerbação das desigualdades sociais e econômicas e do individualismo, imprescindíveis, segundo a sua lógica, ao aumento da competitividade, que, por sua vez, é o motor da economia de mercado.

Dessa forma, observa-se que a educação potencializa o fortalecimento do mercado e a valorização do capital humano, associada a uma concepção produtivista, pautando-se em critérios induzidos pela lógica do capital.

Nos anos 1960, a teoria do capital humano, já destacava a qualificação profissional como principal requisito para empregabilidade e para a produtividade do trabalhador. Para essa teoria, a educação, segundo Kuenzer (2002, p. 60) "[...] se fundamenta na articulação entre política e produção e cujo objetivo é educar o homem capaz de ajustar-se à produção racionalizada, constituindo-se em uma das formas pelas quais a classe burguesa busca concretizar o seu projeto hegemônico".

Reforçando essa perspectiva, as mudanças na educação, sob a lógica da Teoria do Capital Humano, expressas na concepção produtivista, "[...] estava fundada na necessidade de definir um conjunto de estratégias orientadas para criar as condições 'educacionais' de um mercado de trabalho em expansão e na confiança (aparentemente incontestável) de atingir o pleno emprego" (GENTILI, 2002, p. 49).

Diante dessa realidade, Alves e Puziol (2009, p. 7) afirmam que:

No interior dessa teoria vê-se a redução da educação a mero fator de produção. Fica evidente a perspectiva mercadológica que permeia a educação e a corrente preocupação em formar mão-de-obra qualificada para o modo de produção capitalista pautado na organização flexível do trabalho. A partir daí, incorporou-se uma pletora de conceitos chaves capazes de nortear a educação fetichizada para o "cidadão produtivo" na era da globalização com destaque para a noção de competência.

Desse modo, a educação é vista não como um bem social garantido pelo Estado, mas um investimento em que o jovem terá de estudar por si mesmo para adquirir a empregabilidade e o acesso ao mercado de trabalho. Com isso, os indivíduos seriam 
responsáveis pelo próprio desenvolvimento de suas capacidades e competências para ocupar funções exclusivamente técnicas.

No âmbito das transformações ocorridas no século $X X$, sob a égide do neoliberalismo, a educação passa a ser vista como algo meramente lucrativo, capaz de formar o trabalhador para o processo produtivo, "a fim de habilitá-los técnica, social e ideologicamente para o trabalho" (FRIGOTTO,1993, p. 26). Com isso, a educação se caracteriza, não como formadora do cidadão crítico e emancipado, mas como uma aliada do mercado na qualificação de mão de obra para as demandas do capital.

Nesse contexto, o viés adaptativo da educação se caracteriza como "[...] qualidade total, sociedade do conhecimento, educar por competência e para a competitividade, empregabilidade, cidadão ou trabalhador produtivo, etc." (FRIGOTTO; CIAVATTA, 2003, p. 48). Com a economia ancorada aos ditames do capitalismo, consagra-se o termo "cidadão produtivo" com habilidades e competências para maximizar a produtividade e permanência no mercado de trabalho.

Diante disso, o "cidadão produtivo [...] refere-se ao trabalhador capaz de gerar mais valia. O que significa submeter-se às exigências que vão no sentido da subordinação e não da participação para o desenvolvimento de todas as suas potencialidades" (FRIGOTTO; CIAVATTA, 2003, p. 53)

Retratando historicamente a política educacional brasileira, no âmbito das transformações advindas do neoliberalismo, visando potencializar o trabalho alienado, hegemonizado pelo o capital financeiro, a educação foi submetida às orientações das agências multilaterais, particularmente, o Banco Mundial, conforme afirma Oliveira (2002). Essas orientações resultaram na aprovação da Lei de Diretrizes e Bases da Educação Nacional (Lei no 9.394/96), em seus Artigos 35 - II, que objetiva, "a preparação básica para o trabalho e a cidadania do educando, para continuar aprendendo, de modo a ser capaz de se adaptar com flexibilidade a novas condições de ocupação e aperfeiçoamento posteriores". (BRASIL, 1996).

Para Oliveira (2002), a reforma do Ensino Médio, ao estabelecer a responsabilidade de formar para uma atividade específica no mercado de trabalho, retira, do seu interior, os conteúdos fundamentais para uma formação integral do aluno, contribuindo para a exclusão dos estudantes, das camadas populares, o acesso a conteúdos fundamentais ao exercício da cidadania.

De acordo com Frigotto, Ciavatta e Ramos (2005), a regressão mais profunda da LDB, aprovada nos anos 1990, ocorreu com o Decreto 2.208/97 que reestabeleceu a dualidade educacional, assumindo, o ideário pedagógico do capital ou do mercado, pautados na pedagogia das competências para a empregabilidade. 
Assim, as políticas educacionais ligadas às teses neoliberais se justificam com base na necessidade de formar o jovem cidadão capacitado para a integração do modelo da economia globalizada. No entanto, as consequências desse modelo são desastrosas para o trabalhador, visto que o modelo neoliberal e sua reestruturação produtiva, no geral, têm afetado as relações de trabalho, ampliando a situação de desemprego e falta de condições de trabalho através da precarização e da desregulamentação.

De acordo com Antunes (2015), a sociedade contemporânea globalizada presencia um cenário crítico, pois a lógica do sistema produtor vem convertendo a concorrência e a busca da produtividade num processo destrutivo que tem gerado uma sociedade dos excluídos e dos precarizados.

Neste cenário de crise estrutural, "[...] destrói-se a força humana que trabalha, destroçam-se os direitos sociais; brutalizam-se enormes contingentes de homens e mulheres que vivem do trabalho, [...] criando-se uma monumental sociedade do descartável”. (ANTUNES, 2015, p.225).

Diante das mudanças no mundo social do trabalho, a educação apresenta-se como campo de disputa hegemônica. Nessa perspectiva, Oliveira (2009, p.149), afirma que:

Como no âmbito do regime capitalista, as mudanças na forma de organização e de gestão do processo de produção objetivam a perpetuação do processo de exploração da classe trabalhadora e, por conseguinte, a afirmação da dominação burguesa; o principal agente responsável pelas transformações é o próprio capital.

No atual contexto, em que a pedagogia do trabalho é perpassada por profundas contradições que marcam a relação trabalho e educação, é necessário refletir sobre a construção de um projeto contra hegemônico que consiga romper com a lógica da racionalidade financeira, e formar um novo tipo de cidadão ético e politicamente comprometido com a construção de uma sociedade igualitária.

Partindo dessas análises, de acordo com Silva e Fonseca (2012), a configuração no ensino de História na Educação Básica no final do século $X X$ e início do século $X X I$, pautado no ideário neoliberal, está ligado à dimensão econômica, no que diz respeito à formação de habilidades e competências necessárias à constituição de um trabalhador consumidor para o mercado; e à dimensão política, com finalidade da formação básica para o exercício da cidadania.

\section{Os desafios de ensinar História na atualidade}


No contexto de influência da política neoliberal sobre a educação, os historiadores e demais profissionais que atuam no campo educacional deparam-se com inúmeros desafios que regem diariamente a prática pedagógica. Lutar pela construção de um posicionamento crítico dos alunos diante da realidade social e das mutações temporais é fundamental para conduzi-los na busca da sua emancipação enquanto cidadão.

No entanto, é necessário problematizar como o ensino de História tem se enquadrado diante de tais transformações socioeconômicas e políticas e como tem se estabelecido na perspectiva educacional influenciada pelos interesses neoliberais. Diante desse contexto, consideramos que o ensino de História pode contribuir para que o estudante enfrente os desafios da sua realidade social, bem como buscar alternativas de educá-lo para que se torne um cidadão emancipado.

Com o fim da Ditadura Militar, a disciplina História volta a atuar nas propostas curriculares de maneira mais autônoma. Nesse contexto de reabertura política, muitos filhos de trabalhadores "começaram a ocupar os bancos das escolas que, até então, haviam sido pensadas e organizadas para setores privilegiados ou da classe média ascendente" (BITTENCOURT, 2013, p.13).

Diante desse cenário, os professores de História buscavam participar da elaboração das propostas curriculares com o intuito de formular algo que contribuísse de maneira mais eficiente para as dificuldades enfrentadas dentro do contexto escolar, bem como as mudanças que envolvem a sociedade capitalista globalizada.

Nesse período de transição democrática, entre as décadas de 1980 e 1990, foram intensos os debates sobre os rumos a serem dados à educação brasileira. Em relação à Educação Básica, os pesquisadores do campo do trabalho e educação defendiam uma educação unitária, omnilateral e politécnica, capaz de romper com as dicotomias entre a formação geral e específica. Com isso, afirmava-se a necessária vinculação da educação à prática social e o trabalho como princípio educativo.

A concepção de trabalho como princípio educativo, no seu sentido ontológico e éticopolítico, equivale a dizer que o ser humano é produtor da sua realidade, pois dela se apropria e pode transformá-la, a fim de tornar-se sujeito de sua própria história. Saviani (2007) reforça que os fundamentos conceituais da proposição do trabalho como princípio educativo se resumem no trabalho como base da existência humana, na medida em que os homens agem sobre a natureza, transformando-a e ajustando às suas necessidades.

No tocante à politecnia, esta, por sua vez, caracteriza-se como o domínio dos fundamentos científicos das diferentes técnicas utilizadas na produção moderna, que, a partir da abordagem marxista, implica união entre a escola e trabalho, ou, mais 
especificamente, entre instrução intelectual e trabalho produtivo e, com isso, proporcionar a todos uma compreensão do mundo do trabalho.

Para Saviani (1997), a proposta de concepção marxista de educação, formulada pela LDB (9.396/96), no curso dessa trajetória ficou apenas menções genéricas, inconsistentes e ambíguas ao conceito de politecnia. Embora abordasse a concepção da relação trabalho, educação e formação integral humana ou omnilateral dos indivíduos para o exercício da cidadania, não assegurou o seu desenvolvimento na prática.

Outro ponto bastante evidenciado no texto da Lei de Diretrizes e Bases da Educação (LDB - Lei no 9.394/96) é a preparação para o exercício da cidadania. Conforme o seu artigo 2o: "Educação é dever da família e do Estado, inspirada nos princípios de liberdade e nos ideais de solidariedade humana, tem por finalidade o pleno desenvolvimento do educando, seu preparo para o exercício da cidadania e sua qualificação para o trabalho" (BRASIL, 1996).

Está explicito em lei que o Estado tem a competência para conduzir e preparar o educando para o pleno exercício da cidadania e para trabalho. Entretanto, ao longo do tempo o conceito de "cidadania" sofreu mudanças de sentido em diferentes contextos históricos. $\mathrm{Na}$ atualidade, vem sendo bastante apropriado pelo modelo capitalista e neoliberal que ressignificou seu sentido. Assim, a lógica capitalista atribui o termo cidadania a uma "concepção universalizante dos direitos humanos (políticos, sociais, econômicos, culturais etc.) que acaba gerando um conjunto de falsas promessas caracterizadas pela improdutividade, pela falta de reconhecimento social" (GENTILI, 2002, p.48), e pela criação de um cidadão competitivo, aquele que é o único responsável pelo seu sucesso ou fracasso e está apto a se adaptar as mudanças no mundo do trabalho.

No âmbito do ideário pedagógico, o neoliberalismo firmou as "noções de polivalência, qualidade total, empregabilidade do cidadão produtivo (um trabalhador que maximize a produtividade) sendo um cidadão mínimo". (FRIGOTTO; CIAVATTA, 2003, p.52)

Vê-se que, esses posicionamentos acabam refletindo as inúmeras crises que temos vivenciado e que abrangem os diversos setores da sociedade, por isso, tornam-se relevantes as discussões que regem as diversas formas de organização do trabalho, bem como as reflexões sobre as metamorfoses sociais e políticas ao longo da história.

Bittencourt (2013) afirma que foi justamente por meio dessas transformações sociais que as propostas curriculares também sofreram alterações "passou a serem repensadas sob novas perspectivas relacionadas às mudanças sociais e econômicas em curso no país, à mundialização e as transformações do papel e do poder do Estado na nova ordem mundial econômica" (BITTENCOURT, 2013, p.18). 
Em grande parte das propostas curriculares, podemos encontrar que o ensino de História tem como uma das suas finalidades:

Contribuir para a formação de um "cidadão crítico", para que o aluno adquira uma postura crítica em relação à sociedade em que vive. Ao se estudar as sociedades passadas, tem como objetivo básico fazer o aluno compreender o tempo presente e perceber-se como agente social capaz de transformar a realidade, contribuindo para a construção de uma sociedade democrática (BITTENCOURT, 2013, p.19).

De acordo com essa finalidade do ensino de História, a formação do pensamento crítico está diretamente relacionada à compreensão e transformação da realidade social vivenciada. A expressão "sentir-se sujeito histórico" (BITTENCOURT, 2013, p. 19) reflete a formação da cidadania ativa e a emancipação social e política por parte dos estudantes.

No âmbito das instituições escolares, percebemos um público de estudantes extremamente diversificado, que possuem uma pluralidade cultural. É, por meio dessas diferenças, que devemos buscar uma aprendizagem sócio-interacionista. De acordo com Fonseca (1993), para realizarem essa integração, os professores podem inseri-los no processo de ensino-aprendizagem de maneira ativa, isto é, buscando métodos para incentivar os alunos a serem agentes da sua própria história, instigando-os para desenvolverem reflexões e análises sobre os desafios que permeiam o mundo do trabalho e a sua vivência de maneira geral para que possam desenvolver sua criticidade.

No entanto, ensino de História vem sofrendo para conseguir executar essa finalidade, uma vez que com a influência neoliberal, sobretudo no que diz respeito à competitividade, nota-se que há um discurso bastante presente sobre a disciplina colocando-a apenas para servir de auxílio na progressão dos estudos e "passar no ENEM" (Exame Nacional do Ensino Médio).

Mas, ensinar História vai muito além da preparação para o ENEM, por exemplo. Um dos desafios é vincular seus princípios e conceitos à formação integral. Ciavatta (2010, p. 85) justifica que:

[...] com a formação humana, o que se busca é garantir ao adolescente, ao jovem e ao adulto trabalhador o direito de uma formação completa para leitura do mundo e para a atuação como cidadão pertencente a um país, integrado dignamente à sua sociedade política. Formação que, neste sentido, supõe a compreensão das relações sociais subjacentes a todos os fenômenos.

A perspectiva evidenciada por Ciavatta (2010) relaciona-se com a Educação Profissional, uma das modalidades de ensino e educação, pela qual justifica que a Educação Básica deve integra-se às múltiplas dimensões da vida do jovem educando, tornando-o um sujeito ativo e politizado e não apenas um executor de funções específicas. 
Contemplar a omnilateralidade na formação básica do jovem enquanto cidadão constitui-se como algo indispensável. Essa formação de caráter omnilateral busca atingir três dimensões que são fundamentais nos processos educativos: o trabalho, a ciência e a cultura. A primeira dimensão, o trabalho, é compreendido como algo próprio da vida do ser humano que desde o início da humanidade utilizou a racionalidade para transformar a natureza de acordo com as suas necessidades, portanto, possui, nesse sentido, um valor de uso. A ciência é caracterizada como a produção dos conhecimentos desenvolvidos pela humanidade ao longo da história. Por último, a cultura é compreendida como as diversas manifestações artísticas bem como os princípios étnicos que envolvem as normas da sociedade.

Bittencourt (2013) cita o pensamento do historiador André Segal o qual afirma que há uma falta de valorização dessa integralidade do indivíduo nos níveis fundamental e médio da Educação Básica. Segundo o autor, a História tem o papel de contribuir para a formação do jovem que, mesmo estando em pleno processo de desenvolvimento físico e mental, enfrenta um cotidiano complexo, tendo inúmeros problemas como a violência, desemprego, greves, falta de perspectivas com relação a oportunidades de crescimento profissional e, por isso, necessita refletir sobre todos esses acontecimentos que estão a sua volta.

Paulo Freire (2005), na obra Pedagogia do Oprimido, destaca a relevância de se dialogar sobre a realidade vivenciada, expressando que "[...] se os homens são produtores desta realidade e se esta, na inversão de práxis, se volta sobre eles e os condiciona, transformar a realidade opressora, é tarefa histórica, é tarefa dos homens" (FREIRE, 2005, p. 16). Freire faz menção à ação emancipatória que o jovem educando precisa deter para que sua vivência não seja tão somente de dominação e exclusão.

A obtenção de uma postura crítica e libertadora por parte dessa juventude que encontra-se em plena transformação não constitui-se uma tarefa fácil. Na maioria dos casos, o jovem, enquanto sujeito histórico, encontra-se adaptado à sua realidade de opressão, algo que acaba contribuindo para que se mantenha e, ao mesmo tempo, se reproduza uma estrutura social na qual existem os privilegiados e os oprimidos. Freire (2005, p.19) explica que:

Os oprimidos, contudo, acomodados e adaptados, imersos na própria engrenagem de estrutura dominadora, temem a liberdade, enquanto não se sentem capazes de correr riscos de assumi-la. E terem, também, na medida em que, lutar por ela, significa uma ameaça, não só aos que a usam para oprimir, como seus proprietários, mas aos companheiros, que se assustam com maiores repressões.

Diante dessa conjuntura, o professor de História precisa ser um educador crítico que reconheça as diversas situações contraditórias gerenciadas pela sociedade capitalista. É 
importante que ele problematize, juntamente com o aluno, a respeito das contradições que encontram-se materializadas na vida cotidiana, promovendo, assim, diálogos acerca das visões de mundo por parte de cada segmento social e suas formas de atuação.

Quando o historiador-educador problematiza, na sua prática pedagógica, as ideias relacionadas à reprodução social e à subordinação aos moldes da produção capitalista, está trilhando o caminho para que seus alunos adquiram uma educação emancipatória, autônoma e uma posição crítica da realidade. Por isso, ele compreende que as diversas áreas do saber, História, Política, Filosofia, Economia, entre outras, devem ser ensinadas numa perspectiva de vinculação com as experiências de vida dos alunos.

É a partir dessas análises que o professor irá refletir sobre sua prática, bem como propor mudanças no que diz respeito ao ensino e à aprendizagem, sempre tendo como propósito maior a autonomia intelectual, política e social dos alunos diante de uma realidade extremamente voltada para o individualismo e interesses capitalistas.

\section{Conclusão}

Neste artigo, refletimos acerca das perspectivas de se trabalhar a História como formação educacional integral e emancipatória, bem como as dificuldades encontradas para o desenvolvimento dessa prática, além disso, permitiu analisar a conjuntura das políticas neoliberais e sua inserção nos projetos educacionais.

De modo geral, o ensino de História vem buscando cumprir com uma das suas principais finalidades, nessas últimas décadas, que é estimular o educando a realizar uma leitura crítica do meio social no qual está inserido. No entanto, é notório que educadores sofrem constantes desafios na sua prática pedagógica, em decorrência das pressões capitalistas que viabilizam a educação como mecanismo para atender cada vez mais os interesses do mercado de trabalho, direcionando uma formação conteudista, unilateral, específica e aligeirada que não possibilitam reflexões mais profundas acerca da realidade social vivenciada.

De acordo com a importância do tema, torna-se necessário o desenvolvimento de projetos educacionais que tenham como foco a formação omnilateral do indivíduo para que este possa ter acesso não somente aos conhecimentos específicos, mas também a uma formação que esteja atrelada à compreensão dos desafios sociais que o cerca, possibilitando um ensino de maior qualidade para que o jovem torne um ser humano político e socialmente emancipado. 


\section{REFERÊNCIAS}

ALVES, Giovanni; PUZIOL, Jeinni. As metamorfoses do mundo social do trabalho e a educação profissional. In: SEMINÁRIO NACIONAL DE ESTUDOS E PESQUISAS: HISTÓRIA, SOCIEDADE E EDUCAÇÃO NO BRASIL, 7, 2009, Campinas. Anais... Campinas: UNICAMP: 2009.

ANTUNES, Ricardo. Adeus ao trabalho? Ensaio sobre as metamorfoses e a centralidade do mundo do trabalho. 16. ed. São Paulo: Cortez, 2015.

BITTENCOURT, Circe. Capitalismo e cidadania nas atuais propostas curriculares de História. In: (Org.) O saber histórico na sala de aula. 12. ed. São Paulo: Contexto, 2013.

BRASIL, Lei no. 9.394, de 20 de dezembro de 1996. Estabelece as Diretrizes e Bases da Educação Nacional. Disponível em: http://portal.mec.gov.br/seed/arquivos/pdf/tvescola/leis/lein9394.pdf > Acesso em: 18 out. 2017.

CIAVATTA, Maria. A formação integrada: a escola e o trabalho como lugares de memória e de identidade. In: FRIGOTTO, Gaudêncio; CIAVATTA, Maria; RAMOS; Marise. (Orgs.). Ensino Médio Integrado: Concepções e contradições. 2. ed. São Paulo: Cortez, 2010. FONSECA, Selva Guimarães. Caminhos da História ensinada. 13. ed. Campinas: Papiros, 1993.

FREIRE, Paulo. Pedagogia do Oprimido. 34. ed. Rio de Janeiro: Paz e Terra, 2005.

FRIGOTTO, Gaudêncio. A produtividade da escola improdutiva: um (re)exame das relações entre educação e estrutura econômico-social capitalista. São Paulo: Cortez, 1993.

FRIGOTTO, Gaudêncio; CIAVATTA, Maria. Educar o trabalhador cidadão produtivo ou ser humano emancipado? Revista Trabalho, Educação e Saúde. Rio de Janeiro. v. 1, n.1, p. 45-60, 2003.

FRIGOTTO, Gaudêncio; CIAVATTA, Maria; RAMOS; Marise. (Orgs.). Ensino médio integrado: concepções e contradições. São Paulo: Cortez, 2005.

GENTILI, Pablo. Neoliberalismo e educação: manual do usuário. In: GENTILI, Pablo; SILVA, Tadeu. (Orgs.). Escola S. A. quem ganha e quem perde no mercado educacional do neoliberalismo. Brasília: CNT, 1996. p. 9-49.

Três teses sobre a relação trabalho e educação em tempos neoliberais. In: LOMBARDI, José, SAVIANI, Dermeval; SANFELICE, José Luis. (Orgs). Capitalismo, trabaIho e educação. Campinas: HISTEDBR, 2002. p. 45-59.

KUENZER, Acácia. Pedagogia da Fábrica: as relações de produção e educação do trabaIhador. São Paulo: Cortez, 2002. p.60. 
MOURA, Dante. Mudanças na sociedade brasileira dos anos 2000 limitadas pela hegemonia do neoliberalismo: Implicações para o trabalho e para a educação. (Org.). In: Produção de conhecimento, políticas públicas e formação docente em educação profissional. Campinas, SP: Mercado de Letras, 2013. p. 109-138.

Ensino médio e educação profissional: dualidade histórica e possibilidades de integração. In: MOLL, Jaqueline et al (Org.). Educação profissional e tecnológica no Brasil contemporâneo: desafios, tensões e possibilidades. Porto Alegre: Artmed, 2010. p. 58-79.

OLIVEIRA, Ramon. A possibilidade da escola unitária na sociedade capitalista. Cadernos de Educação. Pelotas. p. 141-160. Jan./abr. 2009.

. Ensino Médio e Educação profissional: reformas excludentes. Revista Educar. Curitiba, n. 20, p. 279-298. 2002.

SAVIANI, Dermeval. A Nova Lei da Educação: LDB trajetórias limites e perspectivas. 2 ed. Campinas, SP: Autores Associados, 1997.

. Trabalho e educação: fundamentos ontológicos e históricos. Revista Brasileira de Educação. Campinas, v.12, n.32, p. 52-180, jan./abr. 2007.

SILVA, Marcos. Ensinar história no século XXI: em busca do tempo entendido. SILVA, Marcos; GUIMARÃES, Selva. 4. ed. 2012. Campinas, SP: Papirus, 2012. 